\title{
Nacionalismo metodológico y control subjetivo: una investigación sobre las redes de consejeros y las de accionistas en España y Francia
}

Methodological nationalism and subjective control: an inquiry on networks of directors and shareholders in France and Spain

\author{
Narciso Pizarro Ponce de la Torre \\ Universidad Complutense \\ Aurora Esther Rabazo Martín \\ Universidad de Extremadura \\ npizarro@cps.ucm.es (ESPAÑA)
}

Recibido: 29.102013

Aceptado: 15.07 .2014

\section{RESUMEN}

Esta investigación explora dos problemas teóricos estrechamente ligados: el concepto de control en el gobierno de las empresas y el nacionalismo metodológico implícito en el tipo de conjuntos de datos usados en la mayoría de los análisis estructurales del poder económico. El soporte empírico está constituido por cuatro redes: las de las mayores empresas españolas relacionadas por consejeros comunes, el mismo tipo de red para las mayores empresas francesas y las redes constituidas por las mismas empresas de ambos países relacionas por inversores comunes. Se analizan las consecuencias de elegir uno u otro tipo de relaciones - consejeros comunes o inversores comunes - sobre el carácter nacional de sus respectivas estructuras. Aparece que el uso de redes de relaciones derivadas de los mayores inversores de cada empresa conduce a la difuminación del carácter nacional inicial de los dos conjuntos de empresas. Y también cuestiona las ideas aceptadas sobre la naturaleza del control de la actividad empresarial. 


\title{
PALABRAS CLAVE
}

Redes empresariales, estructuras económicas, consejeros comunes, accionistas comunes, nacionalismo metodológico.

\begin{abstract}
This research explores two theoretical problems that are deeply connected: the concept of control in corporation's governance and the methodological nationalism implicit in the kind of data sets used in most structural analysis of economic power. As an empirical support four networks are used: interlocking directorate's networks of French and Spanish largest firms and the networks of the same corporations in both countries related by common investors. The consequences of choosing one or another kind of relations - interlocking directorates or common investors- on the national character of nationally selected data are analyzed. It appears that the consideration of networks built using the main shareholders of each firm leads to the blurring of the initial national selection of the corporations. And also, challenges standing ideas on the concept of control of corporation's activity.
\end{abstract}

\section{KEY WORDS}

Corporate networks, economic structures, interlocking directorates, common shareholders, methodological nationalism.

\section{INTRODUCCIÓN}

La gran mayoría de los estudios sobre la estructura de la economía, expresada en términos de relaciones inter-empresariales de diferente naturaleza, utilizan como ámbito del análisis la nación. Se trata entonces de describir la estructura económica de una o, en el mejor de los casos, varias naciones. Los datos existentes nos empujan a proceder así, ya que están organizados y clasificados por países, aunque no solamente: también lo están por tipos de actividad económica, por sectores y subsectores.

Otras poderosas razones abogan a favor de estudiar la "economía nacional". Quizás la más importante de ellas sea la dimensión de los datos que hay que analizar, demasiado grande incluso para contemplar la totalidad de las empresas asentadas dentro de las fronteras de un Estado. Pero también lo que convendría llamar el "nacionalismo metodológico" de las ciencias sociales, propiciado por las instancias estatales de financiación de la investigación.

La selección de la nación como ámbito de estudio tiene como principal consecuencia que las conclusiones de la investigación se limiten a una descripción de la estructura económica nacional, corroborando y dando cuerpo a 
la existencia de la misma. Los métodos utilizados en este tipo de investigaciones, además, impiden vislumbrar siquiera las formas de articulación entre ese ámbito nacional y lo que pudiera sobrepasarlo. Cuando se buscan las relaciones entre las empresas de una nación, se encuentran.

Investigaciones como las de Windolf (2002), que describen y comparan las estructuras económicas nacionales entre ellas y que han tenido, y tienen hoy, una considerable influencia en este campo, llevan, como es frecuente en las ciencias sociales, a caracterizar tipos estructurales y a diferenciarlos. Pero aun cuando utiliza datos de varios países, no examina la posibilidad de la existencia de una estructura económica supranacional. Cuando se supera el ámbito nacional se efectúan comparaciones inter- nacionales.

Otras investigaciones, como las de Carroll, sí se han interesado por conectar datos internacionales. En el caso de este autor, bien observando la relación entre los directivos de las mayores empresas mundiales, conectados por la pertenencia a los mismos Consejos de administración (Carroll 2009) o bien buscando la élite corporativa-política formada por aquéllos consejeros de empresas que también forman parte de Consejos de ciertos organismos políticos (Carroll y Sapinski 2010). Sus datos muestran que los consejeros transnacionales están anclados firmemente en una red global, con vínculos entre ellos y con componentes nacionales, pero los networkers nacionales siguen constituyendo la columna vertebral de la élite mundial. Si bien estos trabajos amplían la perspectiva de Windolf y buscan relaciones transnacionales, intentan averiguar si dicha élite tiene conciencia de clase y qué consecuencias conlleva su existencia la integración económica global o una concentración de poder económico y político que amenace la democracia-, cuestiones que, en cualquier caso, no pueden averiguarse simplemente observando los interlocks, como bien recuerda Mizruchi (1996).

El presente trabajo no puede encuadrarse en esta línea de investigación ${ }^{1}$, puesto que no busca élites de personas, sino relaciones entre empresas e indicios sobre la procedencia de su control.

Además del análisis de los consejeros entrelazados, la investigación sobre la red de corporaciones transnacionales se ha llevado a cabo mediante la observación de las relaciones causadas por la propiedad. La excepción más importante respecto a la manera de abordar las estructuras que superan el ámbito de la nación es el excelente trabajo de Vitali (2011), una de las más importantes investigaciones existentes sobre la economía internacional en sentido estricto, que pone de manifiesto la existencia de una estructura de control supranacional de la actividad económica mundial. Este control se estudia en la lógica de las participaciones en el capital de las 40.000 mayores empresas mundiales, tanto directas como indirectas y los resultados ponen de manifiesto la existencia de unas pocas decenas de grandes inversores que constituyen el núcleo del poder económico.

${ }^{1}$ Consultar Carrol y Sapinski (2011) para una revisión de la investigación sobre élites corporativas y redes de empresas.. 
Los resultados de esa investigación, desconocidos para nosotros cuando realizábamos el presente estudio, no solo no contradicen, sino que corroboran en gran medida las conclusiones a las que hemos llegado. Las grandes firmas de inversión identificadas por Vitali y colaboradores están en las listas de los inversores en las empresas francesas y españolas que examinamos, lo que no tiene nada de extrañar. Los inversores que controlan la economía mundial controlan obviamente los fragmentos o partes de esa totalidad que son las empresas que cotizan en Francia y en España.

Con nuestro estudio hemos pretendido realizar una observación ampliada de las relaciones empresariales atendiendo, además de a las creadas por los consejeros, a aquéllas generadas por los accionistas, dentro de dos países y entre ellos, al objeto de mostrar cómo el examen de distintas relaciones entre empresas afecta al carácter nacional de las estructuras que conforman. El trabajo se organiza como sigue: el epígrafe 2 recoge algunos comentarios sobre quién ejerce el control de las entidades, el siguiente se dedica a la metodología tradicional y a la que se va a emplear en esta investigación, en el cuarto epígrafe se muestran los resultados obtenidos y en el quinto se presenta la discusión y conclusiones.

\section{EL CONTROL DE LA ACTIVIDAD EMPRESARIAL}

Las investigaciones sobre la estructura de una economía nacional del tipo al que el presente trabajo puede ser adscrito se asocian a la problemática del control de la actividad de las empresas (Mizruchi 1996). Y la cuestión del control se plantea en la perspectiva más común y más estéril de las teorías del poder: el poder sería la capacidad de un sujeto de obligar a otro a actuar de una manera determinada. Es la posición de Max Weber, entre miles de otros autores que sostienen lo mismo con matices de escasa relevancia.

Repasando a grandes pinceladas, y sin ánimo de exhaustividad, momentos de especial interés en la investigación sobre el control de la actividad empresarial, podríamos remontarnos a comienzo de los años 30, en los tuvieron origen las teorías gerenciales que propusieron que los tecnócratas y/o directivos ostentarían el control del sistema económico, arrebatándoselo a los propietarios privados. Posteriormente, con la aportación de Berle y Means de 1932, comenzó una relevante línea de investigación en la que se establecía que los verdaderos controladores de la economía eran los gerentes, a costa de la pérdida de poder de los propietarios privados. El momento álgido de estos planteamientos llegó con la contribución de Burham (1941) y su revolución gerencialista, que dio lugar a una importante proliferación de textos sobre la decadencia de la burguesía propietaria y el creciente poder de los gerentes. Y fue así hasta los años 60, a partir de los cuales comenzaron a tomar peso los estudios que demostraban que los miembros de los Consejos de Administración e incluso, en ciertos casos, los propietarios influían en decisiones económicas y políticas de modo sustancial. Autores como Zeitlin (1974) realizaron concienzudas críticas de las propuestas 
anteriores e hicieron reflexionar sobre la adecuación de la metodología seguida hasta el momento para alcanzar las conclusiones de los gerencialistas. Para responder al debate sobre si efectivamente se había producido la separación de la propiedad y el control, Zeitlin proponía investigar las relaciones complejas en las que la corporación sólo es un implicado, a saber: el patrón particular de la propiedad y su evolución dentro de la corporación; las relaciones entre ésta y otras corporaciones; las formas de interrelación entre consejeros y entre los directivos, y los consejeros y principales familias accionistas; las conexiones con los bancos, la red de principales participaciones comunes, etc. Es decir, "explorar en detalle la estructura institucional y la clase en la que las grandes corporaciones individuales están situados" (p. 1108). Desde entonces, no se ha llegado a una conclusión comúnmente admitida sobre este particular, pero sí parece que se hayan seguido las recomendaciones de Zeitlin y se estén investigando con más o menos acierto, las relaciones entre corporaciones desde distintas perspectivas.

\section{Los Consejos de Administración y el control de la empresa}

Dado que el poder, concebido como se indicó arriba y según las bases del gobierno corporativo lo tiene en la empresa su Consejo de Administración, el estudio de dichos órganos y de las relaciones existentes entre ellos se presenta como una aproximación al estudio del poder económico.

La atribución del poder empresarial a los Consejos de Administración ha sido cuestionada más de una vez en los últimos años. Los accionistas afirman el carácter prioritario de sus intereses frente a los Consejos, acusados de promover los suyos propios. Y se han producido conflictos entre accionistas y consejeros, centrados básicamente en la rentabilidad de la inversión que se expresa en las magnitudes financieras utilizadas en las bolsas de valores.

\section{Los vínculos entre empresas y entre consejeros}

Las relaciones existentes entre las empresas por la existencia de consejeros comunes en los Consejos de unas y otras, así como la red de relaciones que se teje entre los consejeros de distintas empresas, han constituido un campo de investigación que tiene ya una larga historia. Esta historia se narra en distintos tonos, con finalidades muy diferentes: desde la denuncia de prácticas monopolistas encubiertas que se producen mediante estas relaciones y que la célebre Ley Clayton de 1914 intenta impedir, hasta las investigaciones de Mills (1956) o de Domhoff (1967) y, naturalmente, las investigaciones contemporáneas sobre las redes de empresas y de sus consejeros. Los investigadores empíricos de consejerías cruzadas no han desistido en su empeño por hallar patrones de conexión entre las empresas. Según Bazerman y Schoorman (1983:206), fueron Koening, Gogel y Sonquist (1979) quienes sugirieron que había cuatro modelos dominantes de la existencia de estas 
interrelaciones: el modelo de control gerencial (management control model), el modelo de control financiero (financial control model), el modelo de hegemonía de clase (class hegemony model) y el modelo de reciprocidad (reciprocity model). De los comentarios de Koening et al (1979), Mintz y Schwartz (1981), Bazerman y Schoorman (1983) y Mizruchi (1996) se extraen las principales asunciones de estos modelos y las interpretaciones dadas a las consejerías cruzadas:

- modelo de control gerencial: asume que las decisiones importantes de la empresa son tomadas por el equipo gestor, de modo que el Consejo de Administración es una mera herramienta que proporciona consejo, crítica, prestigio o, en menor grado, contactos de negocios. Las consejerías cruzadas son consideradas poco importantes y se presupone que las empresas tienen pocos incentivos para generar estos enlaces.

- modelo de control financiero: propone que los bancos y compañías de seguros ostentan un gran poder debido a la gran dependencia de recursos financieros de las empresas. Las consejerías cruzadas se establecen, en este caso, entre la institución financiera y la empresa financiada, de modo que la primera puede vigilar su inversión e incluso forzar decisiones que no maximizan los intereses de la segunda, convirtiéndose así, en la única parte beneficiada de la interconexión.

- modelo de hegemonía de clase: centrándose en los individuos y no en las firmas, este modelo sugiere que las consejerías cruzadas no tienen como principal objetivo enlazar empresas, sino conectar a los miembros de una clase superior con poder económico y prestigio social. Estos consejeros comparten tendencias políticas y/o religiosas, tiene la misma visión de la realidad e incluso pueden ser miembros de los mismos clubs. Mediante los Consejos, los componentes de esta élite superior promueven sus intereses pactados, eligiendo, por ese motivo, consejeros que conserven y fortalezcan su hegemonía.

- modelo de reciprocidad: establece que dos compañías deciden compartir consejeros en la creencia de que ambas van a obtener un beneficio con su conexión, el cual puede residir en una coordinación vertical u horizontal, o en la utilización de la experiencia, conocimientos o prestigio que dichos consejeros aportan. Concretamente, estas alianzas pueden desembocar en la eliminación de competidores, la fijación de precios o la limitación del poder de los suministradores. En líneas generales, la elección de los consejeros se basa en su adecuación para disminuir incertidumbres ambientales.

Estos modelos, que son el producto de investigaciones teóricas y empíricas, no han estado libres de crítica. Por ejemplo, Bazerman y Schoorman (1983), exponen sus limitaciones y proponen un modelo alternativo, denominado modelo multinivel de racionalidad limitada que, en su opinión, proporciona un marco más integrado en el que comprender las consejerías cruzadas. En él se sugiere que éstas integran decisiones, relativamente independientes, hechas por los consejeros, la sociedad y las organizaciones involucradas, de modo que cada elector evalúa los pros y contras del enlace en base a un sistema de limitaciones de racionalidad. 
Las investigaciones más recientes (Stokman et al 1985, Mizruchi 1996, Windolf 2002, Cronin 2011, Connelly and Van Slyke 2012) ponen en evidencia que las redes de consejeros constituyen, por decirlo en estos términos, la dimensión política de la estructura económica nacional. Es decir, la existencia de relaciones entre los miembros de los Consejos hacen de ellos más que un mero conjunto de individuos: porque existe esa red, el conjunto deviene grupo y el grupo, un sujeto.

\section{Accionistas y control}

Una de las perspectivas sobre la consideración de los accionistas de las empresas analizadas como actores importantes en lo que al control de la actividad empresarial se refiere, reduce la cuestión del poder de los accionistas a la del poder de los consejeros: los accionistas están representados en los Consejos de Administración por consejeros elegidos mediante sus votos, ponderados por el número de acciones que poseen. Sin embargo, este planteamiento se puso en duda a partir del trabajo de Useem (1996). Sus datos mostraron el nivel de poder alcanzado por los inversores institucionales, además de las vías mediante las que dichos inversores habían ampliado su alcance en la toma de decisiones de la alta dirección y los obstáculos que tenían que salvar en su objetivo de incrementar dicho poder. Useem documentó el activismo de estos inversores por conseguir la mejora del rendimiento empresarial y su éxito al proponer nuevas formas de gobierno, al conseguir despidos de ejecutivos o cambios en la composición de los Consejos de Administración, etc. Por otro lado, también mostró que las respuestas del top management a dichas presiones dieron lugar a mecanismos organizativos y legales de resistencia a las exigencias de los inversores. El autor comenta cómo todo ello unido había desembocado en un nuevo marco en el que los inversores tienen un papel protagonista en la marcha de la economía y cómo se han generado redes de información en ambos sentidos: los gestores dan cuenta del rendimiento de la empresa y los inversores comunican sus preocupaciones. En resumen, Useem puso de manifiesto un considerable cambio en el poder corporativo que obliga a girar la atención hacia la estructura de propiedad.

El estudio encargado por Linklaters (2013) corrobora que los inversores continúan afianzando su protagonismo. La citada investigación ha revelado que los accionistas e inversores activistas han incrementado sus actuaciones de presión sobre las sociedades cotizadas en un $88 \%$ en todo el mundo, aunque principalmente en Europa y Estados Unidos. Los Consejos de Administración europeos se están viendo afectados considerablemente por dicha presión que, si bien en el pasado sufrían más las empresas del sector financiero, en los últimos años se ha extendido a todos los sectores. Por otro lado, los datos muestran que, mientras anteriormente los inversores se habían centrado en la remuneración de los altos directivos, actualmente focalizan sus esfuerzos en conseguir que las empresas empleen el efectivo de los balances para la recompra de acciones, 
para distribuir dividendos especiales o para adquisiciones. En el caso español, el escaso activismo de los accionistas o inversores se venía centrando en las Juntas Generales, pero se ha descubierto un crecimiento significativo del interés de los inversores para ejercer su poder en temas empresariales fundamentales.

Y un claro ejemplo de cómo los inversores pueden ejercer poder en las corporaciones es el magnate Carl Icahn. Uno de los más célebres inversores activistas que tienen como objetivo posicionarse en una empresa para impulsar cambios en el negocio, proponer nuevas metas o modificaciones del equipo gestor. Sus logros en las compañías en las que se implica son tales que la sola noticia de su actuación en una empresa provoca la subida de precios de las acciones. En 2006, uno de los grandes triunfos de Icahn fue conseguir, tras haber convencido a otros accionistas que le proporcionaron apoyo, que se produjera una profunda transformación de la compañía Time Warner, respecto a la que se había marcado como objetivos: una recompra de títulos por más de 20 mil millones de dólares, un plan de reducción de gastos de operación a cambio de no dividir a Time Warner en cuatro empresas independientes, cambios en el Consejo de Administración y, por supuesto, asumir la dirección del grupo.

Podemos asumir, por tanto, la posibilidad de que los principales accionistas en las empresas ejercen un control de la actividad de las mismas que no necesita la mediación de consejeros designados por ellos en los Consejos y que los principales accionistas están vinculados por las empresas en las que invierten, constituyendo una red de accionistas. Así mismo, las empresas están relacionadas por accionistas comunes, lo que genera una red de empresas vinculadas por accionistas. Siendo esto así, el análisis de estas redes nos parece de sumo interés para entender la estructura económica.

\section{El control ejercido por los mercados financieros}

Los grandes inversores, bancos, compañías financieras, compañías de seguros y fondos de inversión participan en muchas empresas: en algunos casos, son miles de participaciones en diferentes empresas las gestionadas por un solo inversor.

Los casos de State Street Corporation y Black Rock Inc. son ejemplos notorios. Ambas tienen inversiones en miles de empresas, 5.841 la primera y 8.241 la segunda. Además, el número de empresas en las que ambas invierten simultáneamente es de 5031. Y dichos ejemplos no son una excepción, ya que lo mismo sucede con los - al menos - 60 mayores inversores mundiales. En el ranking de las 10 primeras empresas inversoras, a parte de las ya citadas, podemos encontrar entidades con situaciones muy similares en cuanto al número de inversiones: Deutsche Bank AG, 5.286; Bank of New York Mellon Corporation, 5.200; JP Morgan Chase \& Co., 5.084; Axa, 4794; Invesco Ltd., 3.948; UBS AG, 3.800; Credit Suisse Group AG, 3.400 y T. Rowe Price Group, Inc., 2.179 .

Es obvio que la gestión de miles de inversiones no puede hacerse mediantes miles de consejeros en los Consejos de Administración de las 
empresas participadas. Y efectivamente no se hace. Existe otro procedimiento, más expeditivo y que puede automatizarse (y que se automatiza mediante ordenadores programados a este efecto): simplemente, vender acciones de las empresas cuyos beneficios van a disminuir o, a la inversa, comprar acciones de aquéllas que las informaciones disponibles hacen pensar que van a aumentar sus ingresos.

Este tipo de decisiones tomadas por inversores concretos se propagan de unos a otros mediante los sistemas informatizados de información bursátil y tienen efectos agregados de considerables dimensiones, con consecuencias muy importantes: en estos años hemos asistido a la invocación de "los mercados" como principal justificación de todo tipo de medidas políticas.

\section{EL MÉTODO UTILIZADO}

El examen de las consejerías cruzadas ("Interlocking directorates", en inglés) ha permitido estudiar dos tipos de redes relacionales: la de empresas, vinculadas por consejeros comunes, y la de consejeros, vinculados por su común pertenencia a un Consejo de Administración o a varios. Este tipo de estructuras ha sido calificado por Breiger (1974) como duales, ya que manifiestan dos visiones diferentes de una misma realidad, la de las relaciones de pertenencia de individuos a grupos, de consejeros a Consejos.

La utilización de este método presupone disponer de datos sobre las pertenencias de consejeros a un conjunto delimitado de empresas. Nada, en principio, impide que este conjunto sea la totalidad de empresas existentes en un país, o en el mundo, en un momento dado. Pero la realidad es que el número total de empresas en un único país es enorme, del orden de cientos de miles, que las existentes en el mundo son millones y, además, que los datos necesarios no son fáciles de obtener y, huelga decirlo, de limpiar, procesar y analizar.

En la práctica, la gran mayoría de las investigaciones que utilizan esta perspectiva metodológica seleccionan un subconjunto de tamaño reducido (del orden del centenar) de empresas. Los criterios utilizados para elegirlas son los del tamaño ("las X mayores empresas"), medido en capitalización bursátil, en volumen de capital social, de beneficios, de empleados, o una combinación cualquiera de estos parámetros u otros similares.

Aunque este tipo de procedimientos se acepta sin mayores reservas, cabe mencionar que su uso está cargado de presuposiciones sobre la naturaleza misma de la estructura empresarial y sobre la del poder económico. La identificación entre el conjunto de consejeros de estas empresas y la élite del poder económico se afirma en ocasiones sin discusión, al menos, sin considerar la eventual discusión de esta identificación como importante. No es evidente que el poder económico resida en los consejeros de los Consejos de Administración de las empresas: pudiera suceder que estos ejerzan funciones principalmente representativas y que no detengan el poder económico efectivo, por lo que es arriesgado identificar al conjunto de los consejeros con una elite económica. 
Dos tipos de datos inducen a pensar que estamos ante una perspectiva poco realista, reductora y engañosa. El primero es el fenómeno de la globalización de la economía mundial, que implica, entre otras cosas, que las naciones no constituyen ámbitos de análisis válidos para describir y analizar la estructura económica. El segundo, no en importancia, es la "financiarización" creciente de la economía, el predominio de instituciones financieras, como bancos, compañías de seguros o fondos de inversión en la estructura económica mundial. Ambos hechos están estrechamente vinculados y producen sus efectos en las economías nacionales.

Las constricciones derivadas del método elegido tradicionalmente al examinar las redes de empresas vinculadas por consejeros comunes impiden vislumbrar la mera presencia de estos efectos de la mundialización y la financiarización en las estructuras económicas nacionales, descritas en términos de relaciones entre empresas mediante consejeros y entre consejeros a través de las empresas en las que coinciden: de entrada se cierra el universo de las relaciones posibles. Y sólo encontramos las que buscábamos.

\subsection{Ampliación de la perspectiva previamente descrita: el estudio de las participaciones en el capital}

Las relaciones entre empresas no se limitan a las que establecen los consejeros comunes. Existen relaciones cliente proveedor, las derivadas de proyectos comunes ("Joint ventures"), las que establecen las transferencias de tecnología, etc. Pero las participaciones en el capital de una empresa por parte de otra tienen una importancia relacional muy significativa ${ }^{2}$.

Si nos limitamos a considerar las relaciones de participación en el capital de una empresa del conjunto seleccionado por parte de otra empresa perteneciente también al conjunto de empresas inicialmente elegido, aumentamos el número de tipos de relaciones considerado, pero mantenemos el ámbito del estudio restringido al conjunto inicial, sin aprovechar las posibilidades que brinda el análisis del accionariado de las empresas seleccionadas.

Existe la posibilidad de considerar todos los principales accionistas de las empresas del conjunto inicialmente seleccionado. Haciéndolo estamos abriendo la perspectiva metodológica y explorando realidades estructurales que se sitúan fuera del ámbito nacional, aun cuando el conjunto de empresas del que se parte

\footnotetext{
2 Algunas estructuras de propiedad pueden emplearse para separar la propiedad del control, como es el caso de las del tipo piramidal (en las el propietario último ejerce el control sobre las firmas ubicadas en los niveles inferiores), y otras, que constituyen patrones mucho más complejos, poseen variados fines o consecuencias, como ocurre con las participaciones cruzadas (en las que las empresas poseen acciones unas de otras, directa o indirectamente a través de una cadena de relaciones). Respecto a estas últimas, se ha demostrado su repercusión desde el punto de vista del poder político (Windolf 2002), de la reducción de la competencia (Gilo et al 2006; Trivieri 2007), o, en el caso de la existencia de altos niveles de enlaces entre instituciones financieras, del aumento del riesgo sistémico (Stiglitz 2010) o de influencia sobre las decisiones de los gerentes postores en la selección de objetivos de adquisición (Hardford et al, 2011)..
} 
esté nacionalmente delimitado y sea de dimensiones reducidas. La lista de inversores institucionales en las empresas consideradas es de mayor tamaño que este conjunto inicial, y además las personas físicas que aparecen como accionistas no coinciden más que en contados casos con los miembros de los Consejos de Administración.

Por las razones ya aducidas, parece que contemplar las relaciones entre un conjunto reducido de empresas nacionalmente delimitado en la perspectiva de las relaciones entre ellas mediante accionistas comunes tiene la capacidad de aportar una perspectiva complementaria respecto a la de las relaciones establecidas mediante los consejeros comunes de sus Consejos de Administración.

Para dar cumplimiento al objetivo de nuestro estudio, examinaremos las principales características de las siguientes redes:

1. Redes de empresas relacionadas por los consejeros comunes.

2. Redes de consejeros conectados por las empresas en las que sirven.

3. Redes de empresas relacionadas por los accionistas comunes.

4. Redes de accionistas conectados por las empresas en las que invierten.

5. Red simple de accionistas de las empresas españolas vinculados a las empresas en las que invierten.

6. Red simple de accionistas de las empresas francesas vinculados a las empresas en las que invierten.

7. Red de accionistas comunes entre Francia y España.

\subsection{REDES DUALES Y REDES SIMPLES}

Conviene resaltar aquí la importancia de las diferencias metodológicas y teóricas existentes en los modos de construcción de las diferentes redes analizadas.

Los cuatro primeros tipos de redes analizados, es decir ocho redes, cuatro por país, son el producto de la conversión de las matrices de incidencia, que expresan las relaciones de pertenencia de elementos a grupos. Son estas redes duales, grafos bipartitos en los que hay dos clases de puntos - los elementos y los grupos - y en los que no existen aristas ni arcos entre puntos de la misma categoría.

La construcción de redes simples derivadas de estas redes bipartitas, que se hace utilizando las multiplicaciones matriciales de las matrices de incidencia por sus respectivas matrices traspuestas (Breiger, 1974) tiene implicaciones que es preciso conocer:

- Primeramente, que las relaciones consideradas son relaciones indirectas y construidas mediante una regla muy clara: se conectan entre sí elementos que pertenecen al mismo grupo y se conectan también, en la red correspondiente, grupos que tienen al menos un elemento común. Concretamente, las redes de empresas vinculadas por inversores comunes 
o las redes de inversores vinculados por invertir en una empresa son redes de este tipo.

- En segundo lugar, que la misma entidad puede figurar en el conjunto de elementos y, al mismo tiempo, en el conjunto de grupos. Por ejemplo, una empresa puede aparecer en la lista de aquellas en las que se invierte y también en la lista de inversores.

- El número de puntos que tienen estas redes es, en un caso, el número de grupos y en el otro, el número de elementos. Es decir, la red de empresas vinculadas por accionistas comunes tendrá un tamaño igual al del conjunto de empresas seleccionado en España (128) o en Francia (127), según el caso. Y las redes de accionistas vinculados por inversiones en las empresas seleccionadas tendrán un número de puntos igual al de inversores identificados: 4631 para España y 1034 en el caso francés.

Muy diferente es el caso de las redes simples que no han sido derivadas de redes duales. En estas redes simples (en inglés "one mode") no existe más que una única categoría de puntos. Y esto implica que:

- El número de puntos de estas redes ni es ni puede ser igual al de las consideradas más arriba, porque inversores y empresas en las que invierten forman parte de la misma red.

- El número de puntos de estas redes tampoco es igual a la suma de los números de empresas consideradas con el número de inversores porque puede suceder y sucede que una o varias de las empresas consideradas en la selección inicial sea también inversora, lo que implica que el número de puntos en la red sea inferior a la suma.

Estas observaciones son necesarias para entender las diferencias de tamaño de las redes derivadas de las relaciones de pertenencia con las redes simples, que se constatan en los datos y análisis expuestos a continuación.

\subsection{Muestra}

Los datos utilizados provienen de la base de datos Osiris y, por motivos de disponibilidad, se ha empleado la información de España en 2009 y la de Francia en 2006.

En ambos casos, las empresas elegidas cotizaban en las Bolsas de Madrid y de París, respectivamente, siendo las más importantes en sus mercados según capitalización. Dicho criterio podría ser discutido debido a que la capitalización de una empresa puede depender de los mercados financieros, del tamaño de la misma y, por supuesto, de su rendimiento. Sin embargo, este criterio, además de los activos totales, suele emplearse con más frecuencia que la cifra de negocios o el número de empleados a la hora de realizar una selección de las empresas más relevantes. Adicionalmente, otro importante motivo que ha condicionado la 
elección de la muestra es la posibilidad de ampliación futura de la investigación mediante estudios confirmatorios. La particularidad de los datos precisados apunta al estudio de las empresas que cotizan en bolsa, ya que de ellas se dispone de información fiable y de más fácil acceso, tanto financiera como de Gobierno Corporativo (en el caso español ésto sucede especialmente en las empresas del mercado continuo).

Como vemos en la siguiente tabla, el tamaño de las muestras es muy similar para los dos países:

Tabla 1. Empresas y consejeros por país

\begin{tabular}{ccc}
\hline & № Empresas & № Consejeros \\
\hline España 2009 & 128 & 1677 \\
Francia 2006 & 127 & 1652 \\
\hline
\end{tabular}

Pero existen diferencias entre las respectivas redes, que ponemos en evidencia a continuación.

\section{RESULTADOS}

\subsection{Empresas y consejeros}

En este primer apartado se comparan los principales aspectos que caracterizan a las redes ${ }^{3}$ de empresas que se relacionan por tener consejeros en común y las redes de consejeros conectados por sentarse en los mismos Consejos de Administración, de España y Francia.

\subsubsection{Características de las redes de empresas vinculadas por los consejeros comunes}

Nos interesamos primeramente en los parámetros que expresan la conectivi$\mathrm{dad}^{4}$. La tabla siguiente es explícita:

Tabla 2. Conectividad de las redes de empresas vinculadas por consejeros

\begin{tabular}{lllll}
\hline & $\mathrm{N}^{\mathrm{o}}$ de puntos & $\mathrm{N}^{\mathrm{o}}$ de aristas & Densidad & Grado medio \\
\hline España & 128 & 171 & 0.021 & 2.67 \\
Francia & 127 & 363 & 0.045 & 5.72 \\
\hline
\end{tabular}

${ }^{3}$ Los conceptos básicos de análisis de redes, como densidad, grado, componentes conexos etc. están claramente definidos en Newman (2003).

${ }^{4}$ La conectividad indica si los individuos están conectados unos con otros, y cómo, a través de la red. 
Puntos: en esta red son las empresas.

Aristas: conexiones no dirigidas entre las empresas.

Densidad: es el número de aristas presentes en la red dividido por el número máximo que podría existir en un grafo, con el mismo número de puntos, si todos estuvieran conectados con todos.

Las empresas francesas tienen más del doble de conexiones mediante consejeros que las españolas, lo que se traduce en una red empresarial con una densidad en este país también más del doble de densa que la española. El grado medio, el número medio de conexiones de una empresa con las demás es también mayor en el caso francés.

\section{Gráfico 3. Grafo ${ }^{5}$ del componente conexo de las empresas españolas vinculadas por consejeros comunes}

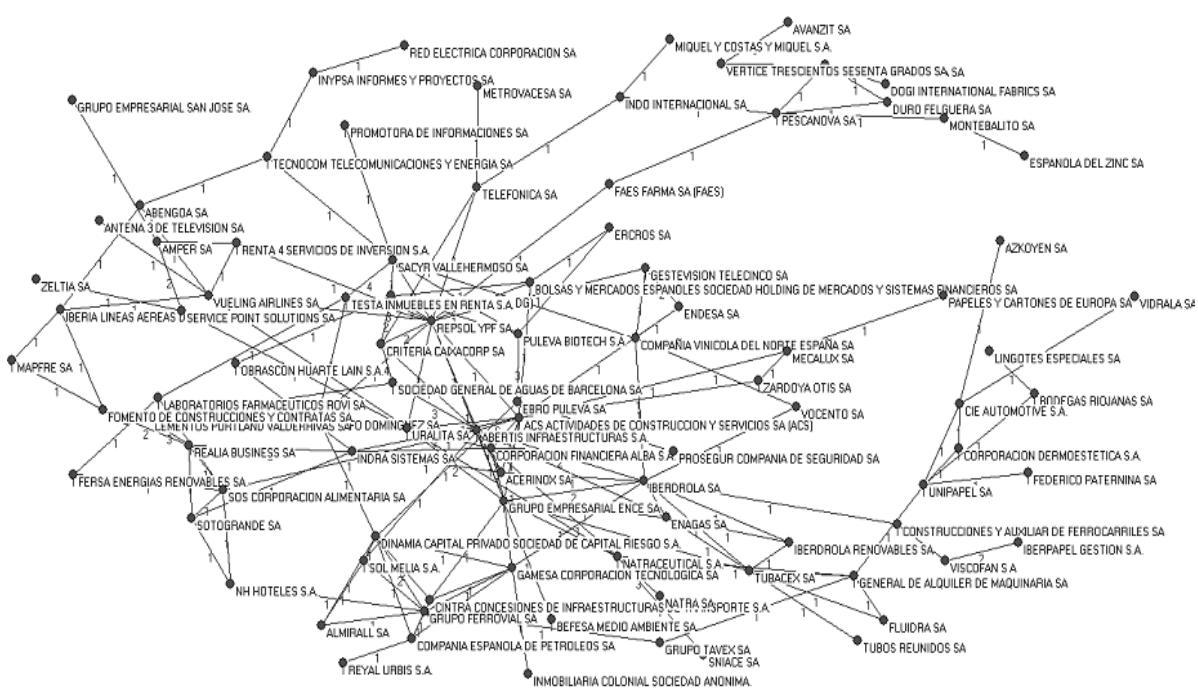

No son éstos los únicos parámetros significativos respecto a la conectividad: el número de componentes ${ }^{6}$ conexos es mayor en la red empresarial española que

${ }^{5}$ Un grafo es un conjunto de elementos llamados puntos, nodos o vértices o y una relación definida sobre el conjunto. Si la relación es asimétrica, ésta se representa por segmentos de línea flechados, denominados arcos, y si la relación es simétrica, se representa por segmentos de línea sin flechar denominados aristas. Grafo conexo es aquel para el que cada par de puntos está conectado por al menos un camino.

${ }^{6}$ Los componentes conexos de un grafo son subgrafos conexos maximales, es decir, subgrafos que incluyen todos los puntos con los que existen conexiones y, naturalmente, entre los que no 
en la francesa. El componente gigante ${ }^{7}$ incluye, en el caso español, a 94 empresas, quedando 34 desconectadas, mientras que en el caso francés el componente conexo gigante tiene 106 empresas, y quedan desconectadas 21 .

\section{Gráfico 3. Grafo del componente conexo de las empresas españolas vinculadas por consejeros comunes}

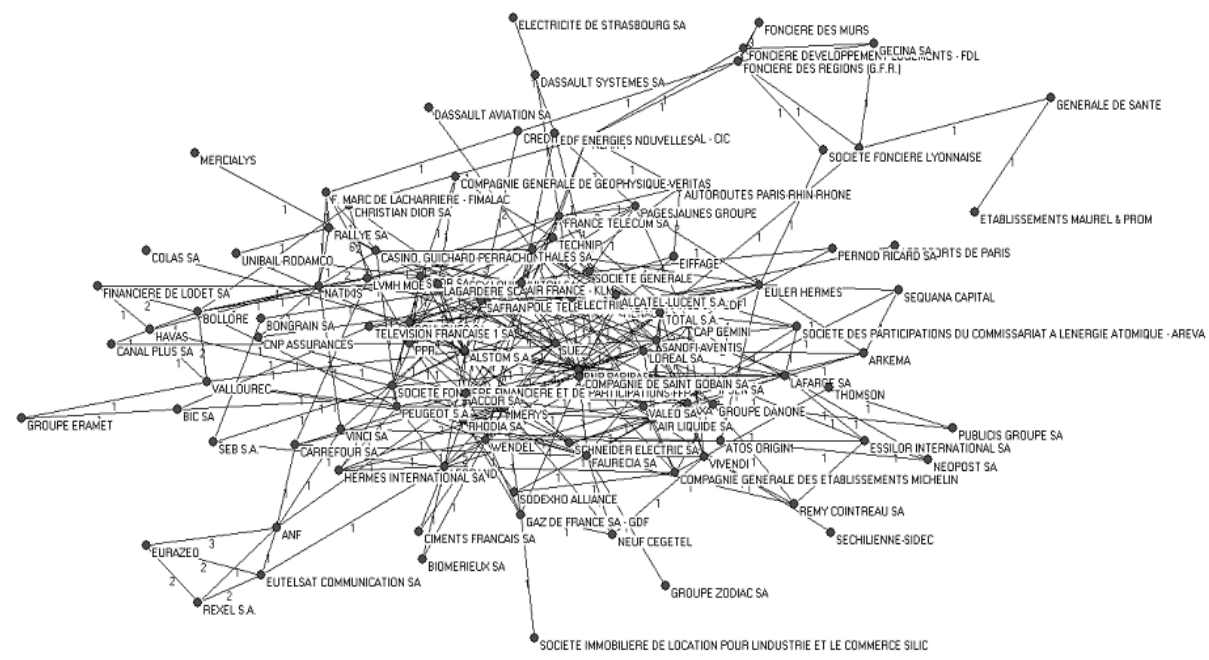

Tabla 3. Componentes y distancias de las redes de empresas vinculadas por consejeros

\begin{tabular}{lcccc}
\hline & $\mathrm{N}^{\mathbf{o}}$ de componentes & $\begin{array}{c}\text { Componente } \\
\text { gigante }\end{array}$ & $\begin{array}{c}\text { Distancia } \\
\text { media }\end{array}$ & $\begin{array}{c}\mathrm{N}^{\mathrm{o}} \text { de aristas } \\
>=2\end{array}$ \\
\hline España & 35 & $94(73,43 \%)$ & 4.22 & 33 \\
Francia & 22 & $106(83,46 \%)$ & 2.89 & 56 \\
\hline
\end{tabular}

Distancia: secuencia de aristas que conectan a un punto con otro.

Distancia media: es la media de las distancias más cortas entre los nodos que conforman la red.

$N^{o}$ aristas con valor superior a 2: número de veces que dos nodos están conectados por dos relaciones, como mínimo. En este caso, por servir juntos en, al menos, dos Consejos.

La distancia media entre las empresas conectadas por consejeros comunes también es mayor en España que en Francia y el número de aristas con valor igual o superior a 2, es decir, empresas con dos o más consejeros comunes es superior en Francia.

existe conexión alguna.

${ }^{7}$ Se llama componente gigante al mayor componente conexo de una red. 
Estos datos ponen en evidencia que, desde el punto de vista de las conexiones empresariales debidas a los consejeros comunes, la red empresarial francesa es significativamente más tupida que la española.

El papel del Estado en la economía francesa tiene diferencias importantes respecto al que desempeña en España. Y no nos referimos aquí a las inversiones públicas, sino al personal de procedencia estatal, a los cuerpos de élite de la administración francesa (ENA, Polytechnique, sobre todo) cuyos miembros forman parte de Consejos de Administración de empresas privadas (véase al respecto Comet y Pizarro, 2011). De cierta manera, podría decirse que la alta conectividad del tejido empresarial francés es el fruto de una política de Estado: la afirmación y defensa de la soberanía nacional pasa también - pero no únicamente - por la consolidación de un conjunto de consejeros de las empresas francesas solidarios, vinculados por trayectorias biográficas similares y por sus relaciones con la alta administración.

En España, por el contrario, el papel de los cuerpos de elite de la administración ha disminuido sin cesar desde 1982: nuestros datos hasta esa fecha sobre la posición de la alta función pública en España, (Baena M., Pizarro N., 1985) (Baena, M., Garrido L., Pizarro N., 1984) muestran una situación más similar a la francesa que la actual. En España la pertenencia a los grandes cuerpos de funcionarios de la administración central del Estado constituyó uno de los principales factores de cohesión de las elites del poder. Ya no es el caso.

\subsubsection{Características de las redes de consejeros vinculados por pertenecer a los mismos Consejos}

Las redes de consejeros son otra forma de ver la misma estructura, dual respecto a las redes de empresas. Contemplaremos los mismos parámetros de conectividad que hemos utilizado con las redes de empresas.

Tabla 4. Conectividad de las redes de consejeros

\begin{tabular}{lcccc}
\hline & $\mathrm{N}^{\circ}$ de puntos & $\mathrm{N}^{\circ}$ de aristas & Densidad & Grado medio \\
\hline España & 1677 & 14110 & 0.010 & 16.827 \\
Francia & 1652 & 17180 & 0.0126 & 20.799 \\
\hline
\end{tabular}

Tabla 5. Componentes y distancias de las redes de consejeros

\begin{tabular}{lcccc}
\hline & $\begin{array}{c}\mathrm{N}^{\circ} \text { de } \\
\text { componentes }\end{array}$ & $\begin{array}{c}\text { Componente } \\
\text { gigante }\end{array}$ & $\begin{array}{c}\text { Distancia } \\
\text { media }\end{array}$ & $\begin{array}{c}\mathrm{N}^{\circ} \text { de } \\
\text { aristas }>=2\end{array}$ \\
\hline España & 35 & $1270(75.73 \%)$ & 4.96 & 560 \\
Francia & 22 & $1464(88.62 \%)$ & 3.64 & 131 \\
\hline
\end{tabular}


Las comparaciones entre las redes de consejeros arrojan resultados interesantes: las diferencias entre las redes de consejeros francesa y española son menores que las existentes en las redes de empresas: la densidad, el grado medio, la media de distancias entre puntos no difieren demasiado. Y existe un dato importante: el número de consejeros vinculados por dos o más empresas es más alto en España que en Francia.

\subsection{Características de las redes de empresas vinculadas por los accionistas comunes}

Entramos ahora en el análisis de un tipo de datos que no ha sido empleado tradicionalmente en las investigaciones sobre las redes empresariales: el de las redes de empresas vinculadas por accionistas comunes y, dualmente, las redes de accionistas vinculados por inversiones comunes en las mismas empresas.

\subsubsection{Características de las redes de consejeros vinculados por pertenecer a los mismos Consejos}

Empleamos los datos de las mismas 128 empresas españolas y las 127 empresas francesas, y en la primera parte del análisis seguiremos las rutinas empleadas anteriormente para el estudio de las redes de consejeros y de empresas vinculadas por éstos.

Los principales parámetros se expresan en las tablas siguientes:

Tabla 6. Conectividad de las redes de empresas vinculadas por accionistas

\begin{tabular}{lcccc}
\hline & $\mathrm{N}^{\mathbf{o}}$. de puntos & $\mathrm{N}^{\mathbf{o}}$ de aristas & Densidad & Grado medio \\
\hline España & 129 & 5939 & 0,72 & 92,12 \\
Francia & 127 & 7208 & 0,900 & 113,51 \\
\hline
\end{tabular}

Tabla 7.Componentes y distancias de las redes de empresas vinculadas por accionistas

\begin{tabular}{lcccc}
\hline & $\begin{array}{c}\mathrm{N}^{\circ} \text {. de } \\
\text { componentes }\end{array}$ & $\begin{array}{c}\text { Componente } \\
\text { gigante }\end{array}$ & $\begin{array}{c}\text { Distancia } \\
\text { media }\end{array}$ & $\begin{array}{c}\mathrm{N}^{\circ} \text {. de aristas } \\
>=2\end{array}$ \\
\hline España & 4 & $126(97.67 \%)$ & 1,246 & 4376 \\
Francia & 3 & $125(98,42 \%)$ & 1,067 & 6639 \\
\hline
\end{tabular}




\subsubsection{Características de las redes de accionistas vinculadas por participar en las mismas empresas}

Las dos tablas que se presentan a continuación evidencian que las redes de accionistas conectados por empresas en ambos países son extremadamente conexas: los componentes conexos gigantes incluyen a más de 99,8 \% de los puntos, las distancias medias entre puntos están alrededor de dos y el número de pares de accionistas conectados por 2 o más empresas es muy alto.

Tabla 8. Conectividad de las redes de accionistas vinculadas por empresas en las que tienen inversiones comunes

\begin{tabular}{ccccc}
\hline & $\mathrm{N}^{\circ}$ de puntos & $\mathrm{N}^{\circ}$ de aristas & Densidad & Grado medio \\
\hline España & 4631 & 337133 & 0,0314 & 145,6 \\
Francia & 1034 & 53833 & 0,10 & 104,125 \\
\hline
\end{tabular}

Tabla 9. Componentes y distancias de las redes de accionistas vinculadas por empresas en las que tienen inversiones comunes

\begin{tabular}{lcccc}
\hline & $\begin{array}{c}\mathrm{N}^{\circ} \text { de } \\
\text { componentes }\end{array}$ & Componente gigante & $\begin{array}{c}\text { Distancia } \\
\text { media }\end{array}$ & $\begin{array}{c}\mathrm{N}^{\mathbf{0}} \text { de } \\
\text { aristas }>=2\end{array}$ \\
\hline España & 4 & $4625(99,87 \%)$ & 2,07 & 18099 \\
Francia & 3 & $1032(99,80 \%)$ & 1,91 & 15296 \\
\hline
\end{tabular}

Las diferencias observadas en las redes de accionistas española y francesa (tamaño del componente gigante) se explican, como veremos más abajo, por el mayor número de accionistas individuales presentes en las empresas españolas (2115 individuos) que los que aparecen en las francesas (198 individuos).

\subsection{Comparaciones de las redes simples (One Mode) de accionistas españolas y francesas}

Examinaremos ahora las redes simples (One Mode) en las que los arcos -no las aristas- conectan al accionista con la empresa en la que invierte. Recordemos que en este tipo de redes, la empresa puede ser, a su vez, inversora en otra empresa, con las consecuencias, ya expuestas anteriormente, respecto al número total de puntos en la red.

\subsubsection{Características de las redes de accionistas vinculadas por participar en las mismas empresas}

El grado de salida de los puntos expresa ahora el número de empresas en las que invierten los accionistas. Vale la pena contemplar frecuencias y porcentajes 
porque existe una diferencia importante entre los números de accionistas de un país y otro, España con 4.375 y Francia con 1.161 accionistas, que incide en las frecuencias absolutas más que en los porcentajes.

Tabla 10. España: inversores por categorías

\begin{tabular}{lccc}
\hline Categoría & Frecuencia & Porcentaje & $\begin{array}{c}\text { Porcentaje } \\
\text { acumulado }\end{array}$ \\
\hline Bancos & 264 & $5,6 \%$ & $5,6 \%$ \\
Estado & 14 & $0,3 \%$ & $5,9 \%$ \\
Financieras & 631 & $13,3 \%$ & $19,2 \%$ \\
Fondos Inversión & 401 & $8,5 \%$ & $27,7 \%$ \\
Fundaciones & 21 & $0,4 \%$ & $28,1 \%$ \\
Individuos & 2.115 & $44,7 \%$ & $72,8 \%$ \\
Industriales & 1.194 & $25,2 \%$ & $98,0 \%$ \\
Seguros & 95 & $2,0 \%$ & $100,0 \%$ \\
\hline TOTAL & 4.735 & $100,0 \%$ & \\
\hline
\end{tabular}

Tabla 11.Francia: inversores por categorías

\begin{tabular}{lccc}
\hline Categoría & Frecuencia & Porcentaje & $\begin{array}{c}\text { Porcentaje } \\
\text { acumulado }\end{array}$ \\
\hline Bancos & 152 & $13,4 \%$ & $13,4 \%$ \\
Estado & 10 & $0,9 \%$ & $14,2 \%$ \\
Financieras & 142 & $12,5 \%$ & $26,7 \%$ \\
Fondos Inversión & 221 & $19,4 \%$ & $46,2 \%$ \\
Fundaciones & 7 & $0,6 \%$ & $46,8 \%$ \\
Individuos & 198 & $17,4 \%$ & $64,2 \%$ \\
Industriales & 335 & $29,5 \%$ & $93,7 \%$ \\
Seguros & 72 & $6,3 \%$ & $100,0 \%$ \\
\hline TOTAL & 1.137 & $100,0 \%$ & \\
\hline
\end{tabular}

Mientras que el orden por importancia de las categorías de inversores en España es: individuos y familias, empresas industriales, empresas financieras, fondos de inversión, bancos, seguros, fundaciones y Estado; en Francia es el siguiente: empresas industriales, fondos de inversión, individuos y familias, bancos, empresas financieras, seguros, Estado y fundaciones. Además de esta diferencia, un aspecto importante que hay que considerar es que en España aparecen 2.115 individuos o familias inversoras, mientras que en Francia sólo lo hacen 198, y esta disparidad incide en las demás categorías de inversores. Este hecho ya se había puesto de manifiesto en anteriores investigaciones, por ejemplo, en el Share Ownership Survey 2007 (FESE; 2008) o en el trabajo de Garmendia y Del Orden (2006). El primero de ellos informaba de que España 
era uno de los 4 países en los que los inversores individuales poseían una participación del más del $20 \%$ del valor de mercado, ostentando el segundo lugar en un ranking de 23 países europeos, en el que Francia ocupaba el décimo noveno puesto; y el segundo mostraba que los individuos y familias eran los protagonistas de la estructura accionarial española, seguidos de las empresas nacionales no financieras.

Además de los tipos de inversores, conviene examinar en cuantas empresas invierten. La distribución por grado de salida suministra una visión interesante:

Tabla 10. España: inversores por grado ${ }^{8}$

\begin{tabular}{lccc}
\hline Grado de salida & Frecuencia & Porcentaje & $\begin{array}{c}\text { Porcentaje } \\
\text { acumulado }\end{array}$ \\
\hline 0 & 104 & $2,2 \%$ & $2,2 \%$ \\
1 & 3.831 & $80,9 \%$ & $83,1 \%$ \\
2 & 406 & $8,6 \%$ & $91,7 \%$ \\
de 3 a 5 & 255 & $5,4 \%$ & $97,1 \%$ \\
de 6 a 10 & 76 & $1,6 \%$ & $98,7 \%$ \\
de 11 a 20 & 38 & $0,8 \%$ & $99,5 \%$ \\
$>21$ & 25 & $0,5 \%$ & $100,0 \%$ \\
\hline TOTAL & 4.735 & $100,0 \%$ & \\
\hline
\end{tabular}

Tabla 11. Francia: inversores por grado

\begin{tabular}{lccc}
\hline Grado de salida & Frecuencia & Porcentaje & $\begin{array}{c}\text { Porcentaje } \\
\text { acumulado }\end{array}$ \\
\hline 0 & 104 & $9,1 \%$ & $9,1 \%$ \\
1 & 688 & $60,5 \%$ & $69,7 \%$ \\
2 & 97 & $8,5 \%$ & $78,2 \%$ \\
de 3 a 5 & 101 & $8,9 \%$ & $87,1 \%$ \\
\hline Grado de salida & Frecuencia & Porcentaje & $\begin{array}{c}\text { Porcentaje } \\
\text { acumulado }\end{array}$ \\
\hline de 6 a 10 & 49 & $4,3 \%$ & $91,4 \%$ \\
de 11 a 20 & 36 & $3,2 \%$ & $94,5 \%$ \\
$>21$ & 62 & $5,5 \%$ & $100,0 \%$ \\
\hline TOTAL & 1.137 & $100,0 \%$ & \\
\hline
\end{tabular}

La primera constatación es interesante: de las 128 empresas españolas y de las 127 francesas seleccionadas, algunas de ellas son también inversoras: 24 en

${ }^{8}$ El que en una red simple de inversores y empresas aparezcan puntos con grado de salida cero es normal: se trata de empresas en las que otros invierten, y ellas mismas no lo hacen y que forman parte de la misma red. 
España y 23 en Francia.

El examen de las tablas de contingencia en las que se cruzan las variables grado de salida con categoría de inversores es de gran interés.

Tabla 14. España: Grado de salida, por intervalos, de las categorías de accionistas

\begin{tabular}{l|c|c|c|c|c|c|c|c}
\hline \multirow{2}{*}{ Categorías } & \multicolumn{7}{|c|}{ Grado de salida por intervalos } & \multirow{2}{*}{ Total } \\
\cline { 2 - 9 } & 0 & 1 & 2 & 3 a 5 & 6 a 10 & 11 a 20 & $>21$ & \\
\hline \multirow{2}{*}{ Bancos } & 10 & 110 & 39 & 39 & 33 & 20 & 13 & 264 \\
& $3,79 \%$ & $41,67 \%$ & $14,77 \%$ & $14,77 \%$ & $12,5 \%$ & $7,58 \%$ & $4,92 \%$ & $100 \%$ \\
\hline \multirow{2}{*}{ Estado } & 0 & 5 & 2 & 3 & 2 & 1 & 1 & 14 \\
& $0 \%$ & $35,71 \%$ & $14,29 \%$ & $21,43 \%$ & $14,29 \%$ & $7,14 \%$ & $7,14 \%$ & $100 \%$ \\
\hline Financieras & 3 & 480 & 71 & 57 & 13 & 3 & 4 & 631 \\
& $0,48 \%$ & $76,07 \%$ & $11,25 \%$ & $9,03 \%$ & $2,06 \%$ & $0,48 \%$ & $0,63 \%$ & $100 \%$ \\
\hline Fondos & 0 & 284 & 53 & 41 & 13 & 7 & 3 & 401 \\
Inversión & $0 \%$ & $70,82 \%$ & $13,22 \%$ & $10,22 \%$ & $3,24 \%$ & $1,75 \%$ & $0,75 \%$ & $100 \%$ \\
\hline Fundaciones & 0 & 18 & 2 & 1 & 0 & 0 & 0 & 21 \\
& $0 \%$ & $85,71 \%$ & $9,52 \%$ & $4,76 \%$ & $0 \%$ & $0 \%$ & $0 \%$ & $100 \%$ \\
\hline Individuos & 0 & 1.908 & 146 & 56 & 5 & 0 & 0 & 2.115 \\
& $0 \%$ & $90,21 \%$ & $6,9 \%$ & $2,65 \%$ & $0,24 \%$ & $0 \%$ & $0 \%$ & $100 \%$ \\
\hline Industriales & 90 & 969 & 83 & 41 & 6 & 3 & 2 & 1.194 \\
& $7,54 \%$ & $81,16 \%$ & $6,95 \%$ & $3,43 \%$ & $0,5 \%$ & $0,25 \%$ & $0,17 \%$ & $100 \%$ \\
\hline Seguros & 1 & 57 & 10 & 17 & 4 & 4 & 2 & 95 \\
& $1,05 \%$ & $60 \%$ & $10,53 \%$ & $17,89 \%$ & $4,21 \%$ & $4,21 \%$ & $2,11 \%$ & $100 \%$ \\
\hline TOTAL & 104 & 3.831 & 406 & 255 & 76 & 38 & 25 & 4.735 \\
& $2,2 \%$ & $80,91 \%$ & $8,57 \%$ & $5,39 \%$ & $1,61 \%$ & $0,8 \%$ & $0,53 \%$ & $100 \%$ \\
\hline
\end{tabular}

En cursiva se expresan las cantidades como porcentajes del total.

Tabla 15. Francia: Grado de salida, por intervalos, de las categorías de accionistas

\begin{tabular}{l|c|c|c|c|c|c|c|c}
\hline \multirow{2}{*}{ Categorías } & \multicolumn{7}{|c|}{ Grado de salida por intervalos } & \multirow{2}{*}{ Total } \\
\cline { 2 - 8 } & 0 & 1 & 2 & 3 a 5 & 6 a 10 & 11 a 20 & $>21$ & \\
\hline \multirow{2}{*}{ Bancos } & 0 & 53 & 14 & 28 & 13 & 9 & 35 & 152 \\
& $0 \%$ & $34,87 \%$ & $9,21 \%$ & $18,42 \%$ & $8,55 \%$ & $5,92 \%$ & $23,03 \%$ & $100 \%$ \\
\hline \multirow{2}{*}{ Estado } & 0 & 1 & 0 & 0 & 2 & 4 & 3 & 10 \\
& $0 \%$ & $10 \%$ & $0 \%$ & $0 \%$ & $20 \%$ & $40 \%$ & $30 \%$ & $100 \%$ \\
\hline \multirow{2}{*}{ Financieras } & 12 & 92 & 14 & 12 & 4 & 4 & 4 & 142 \\
& $8,45 \%$ & $64,79 \%$ & $9,86 \%$ & $8,45 \%$ & $2,82 \%$ & $2,82 \%$ & $2,82 \%$ & $100 \%$ \\
\hline
\end{tabular}




\begin{tabular}{l|c|c|c|c|c|c|c|c}
\hline Fondos & 1 & 128 & 23 & 34 & 19 & 10 & 6 & 221 \\
Inversión & $0,45 \%$ & $57,92 \%$ & $10,41 \%$ & $15,38 \%$ & $8,6 \%$ & $4,52 \%$ & $2,71 \%$ & $100 \%$ \\
\hline \multirow{2}{*}{ Fundaciones } & 0 & 5 & 1 & 1 & 0 & 0 & 0 & 7 \\
& $0 \%$ & $71,43 \%$ & $14,29 \%$ & $14,29 \%$ & $0 \%$ & $0 \%$ & $0 \%$ & $100 \%$ \\
\hline \multirow{2}{*}{ Individuos } & 0 & 184 & 14 & 0 & 0 & 0 & 0 & 198 \\
& $0 \%$ & $92,93 \%$ & $7,07 \%$ & $0 \%$ & $0 \%$ & $0 \%$ & $0 \%$ & $100 \%$ \\
\hline \multirow{2}{*}{ Industriales } & 89 & 193 & 21 & 17 & 6 & 4 & 5 & 335 \\
& $26,57 \%$ & $57,61 \%$ & $6,27 \%$ & $5,07 \%$ & $1,79 \%$ & $1,19 \%$ & $1,49 \%$ & $100 \%$ \\
\hline \multirow{2}{*}{ Seguros } & 2 & 32 & 10 & 9 & 5 & 5 & 9 & 72 \\
& $2,78 \%$ & $44,44 \%$ & $13,89 \%$ & $12,5 \%$ & $6,94 \%$ & $6,94 \%$ & $12,5 \%$ & $100 \%$ \\
\hline \multirow{2}{*}{ TOTAL } & 104 & 688 & 97 & 101 & 49 & 36 & 62 & 1.137 \\
& $9,15 \%$ & $60,51 \%$ & $8,53 \%$ & $8,88 \%$ & $4,31 \%$ & $3,17 \%$ & $5,45 \%$ & $100 \%$ \\
\hline
\end{tabular}

Suprimiendo en los datos franceses y españoles a los accionistas individuales y a las familias, las diferencias en el número total de inversores disminuyen considerablemente, aunque sigue siendo grande. Las tablas siguientes exponen los resultados de esa simple operación.

Tabla 16. España: Grado de salida, por intervalos, de las categorías de accionistas excluyendo a individuos y familias

\begin{tabular}{|c|c|c|c|c|c|c|c|c|}
\hline \multirow{2}{*}{ Categorías } & \multicolumn{7}{|c|}{ Grado de salida } & \multirow{2}{*}{ Total } \\
\hline & 0 & 1 & 2 & 3 a 5 & 6 a 10 & 11 a 20 & $>21$ & \\
\hline \multirow[t]{2}{*}{ Bancos } & 10 & 110 & 39 & 39 & 33 & 20 & 13 & 264 \\
\hline & $0,00 \%$ & $5,64 \%$ & $1,49 \%$ & $2,98 \%$ & $1,38 \%$ & $0,96 \%$ & $3,73 \%$ & $10.08 \%$ \\
\hline \multirow[t]{2}{*}{ Estado } & 0 & 5 & 2 & 3 & 2 & 1 & 1 & 14 \\
\hline & $0,00 \%$ & $0,11 \%$ & $0,00 \%$ & $0,00 \%$ & $0,21 \%$ & $0,43 \%$ & $0,32 \%$ & $0,53 \%$ \\
\hline \multirow{2}{*}{$\begin{array}{l}\text { Financieras } \\
\text { Categorías }\end{array}$} & 3 & 480 & 71 & 57 & 13 & 3 & 4 & 631 \\
\hline & \multicolumn{7}{|c|}{ Grado de salida } & Total \\
\hline \multirow{3}{*}{$\begin{array}{l}\text { Financieras } \\
\text { Fondos } \\
\text { Inversión }\end{array}$} & $1,28 \%$ & $9,80 \%$ & $1,49 \%$ & $1,28 \%$ & $0,43 \%$ & $0,43 \%$ & $0,43 \%$ & $24,08 \%$ \\
\hline & 0 & 284 & 53 & 41 & 13 & 7 & 3 & 401 \\
\hline & $0,11 \%$ & $13,63 \%$ & $2,45 \%$ & $3,62 \%$ & $2,02 \%$ & $1,06 \%$ & $0,64 \%$ & $15,31 \%$ \\
\hline \multirow[t]{2}{*}{ Fundaciones } & 0 & 18 & 2 & 1 & 0 & 0 & 0 & 21 \\
\hline & $0,00 \%$ & $0,53 \%$ & $0,11 \%$ & $0,11 \%$ & $0,00 \%$ & $0,00 \%$ & $0,00 \%$ & $0,80 \%$ \\
\hline \multirow[t]{2}{*}{ Industriales } & 90 & 969 & 83 & 41 & 6 & 3 & 2 & 1194 \\
\hline & $9,48 \%$ & $20,55 \%$ & $2,24 \%$ & $1,81 \%$ & $0,64 \%$ & $0,43 \%$ & $0,53 \%$ & $45.57 \%$ \\
\hline \multirow[t]{2}{*}{ Seguros } & 1 & 57 & 10 & 17 & 4 & 4 & 2 & 95 \\
\hline & $0,21 \%$ & $3,41 \%$ & $1,06 \%$ & $0,96 \%$ & $0,53 \%$ & $0,53 \%$ & $0,96 \%$ & $3,63 \%$ \\
\hline
\end{tabular}




\begin{tabular}{l|c|c|c|c|c|c|c|c}
\hline TOTAL & 104 & 1923 & 260 & 199 & 71 & 38 & 25 & 2620 \\
& $11,08 \%$ & $53,67 \%$ & $8,84 \%$ & $10,76 \%$ & $5,22 \%$ & $3,83 \%$ & $6,60 \%$ & $100,00 \%$ \\
\hline
\end{tabular}

En cursiva se expresan las cantidades como porcentajes del total

Tabla 17. Francia: Grado de salida, por intervalos, de las categorías de accionistas excluyendo a individuos y familias

\begin{tabular}{|c|c|c|c|c|c|c|c|c|}
\hline \multirow{2}{*}{ Categorías } & \multicolumn{7}{|c|}{ Grado de salida } & \multirow{2}{*}{ Total } \\
\hline & 0 & 1 & 2 & 3 a 5 & 6 a 10 & 11 a 20 & $>21$ & \\
\hline \multirow[t]{2}{*}{ Bancos } & 0 & 53 & 14 & 28 & 13 & 9 & 35 & 152 \\
\hline & $0,00 \%$ & $5,64 \%$ & $1,49 \%$ & $2,98 \%$ & $1,38 \%$ & $0,96 \%$ & $3,73 \%$ & $16,19 \%$ \\
\hline \multirow[t]{2}{*}{ Estado } & 0 & 1 & 0 & 0 & 2 & 4 & 3 & 10 \\
\hline & $0,00 \%$ & $0,11 \%$ & $0,00 \%$ & $0,00 \%$ & $0,21 \%$ & $0,43 \%$ & $0,32 \%$ & $1,06 \%$ \\
\hline \multirow[t]{2}{*}{ Financieras } & 12 & 92 & 14 & 12 & 4 & 4 & 4 & 142 \\
\hline & $1,28 \%$ & $9,80 \%$ & $1,49 \%$ & $1,28 \%$ & $0,43 \%$ & $0,43 \%$ & $0,43 \%$ & $15,12 \%$ \\
\hline \multirow{2}{*}{$\begin{array}{l}\text { Fondos } \\
\text { Inversión }\end{array}$} & 1 & 128 & 23 & 34 & 19 & 10 & 6 & 221 \\
\hline & $0,11 \%$ & $13,63 \%$ & $2,45 \%$ & $3,62 \%$ & $2,02 \%$ & $1,06 \%$ & $0,64 \%$ & $23,54 \%$ \\
\hline \multirow[t]{2}{*}{ Fundaciones } & 0 & 5 & 1 & 1 & 0 & 0 & 0 & 7 \\
\hline & $0,00 \%$ & $0,53 \%$ & $0,11 \%$ & $0,11 \%$ & $0,00 \%$ & $0,00 \%$ & $0,00 \%$ & $0,75 \%$ \\
\hline \multirow[t]{2}{*}{ Industriales } & 89 & 193 & 21 & 17 & 6 & 4 & 5 & 335 \\
\hline & $9,48 \%$ & $20,55 \%$ & $2,24 \%$ & $1,81 \%$ & $0,64 \%$ & $0,43 \%$ & $0,53 \%$ & $35,68 \%$ \\
\hline \multirow[t]{2}{*}{ Seguros } & 2 & 32 & 10 & 9 & 5 & 5 & 9 & 72 \\
\hline & $0,21 \%$ & $3,41 \%$ & $1,06 \%$ & $0,96 \%$ & $0,53 \%$ & $0,53 \%$ & $0,96 \%$ & $7,67 \%$ \\
\hline \multirow[t]{2}{*}{ TOTAL } & 104 & 504 & 83 & 101 & 49 & 36 & 62 & 939 \\
\hline & $11,08 \%$ & $53,67 \%$ & $8,84 \%$ & $10,76 \%$ & $5,22 \%$ & $3,83 \%$ & $6,60 \%$ & $100,00 \%$ \\
\hline
\end{tabular}

En cursiva se expresan las cantidades como porcentajes del total

Las comparaciones entre los datos de las redes de accionistas de las empresas francesas y españolas son más claras si se expresan en porcentajes del total de inversores. Pero las diferencias en los números totales deben ser consideradas para apreciar mejor el sentido de las diferencias de porcentajes que pueden observarse. Por ejemplo, los bancos representan el 10,08 \% de los accionistas de las empresas españolas y el 16,19 \% de las francesas. Sin embargo, en valores absolutos, en España son 264 bancos contra 152 en el caso francés. 


\subsubsection{Países de origen de los inversores en Francia y en España}

Una de las dimensiones más interesantes del estudio de los accionistas de las empresas de ambos países es la de la distribución por país de origen. Los siguientes datos son elocuentes.

Tabla 18. Distribución por países de los accionistas de las empresas francesas

\begin{tabular}{lcclcc}
\hline País & Frecuencia & Porcentaje & País & Frecuencia & Porcentaje \\
\hline $\mathrm{AD}$ & 1 & $0,0 \%$ & $\mathrm{~GB}$ & 579 & $11,8 \%$ \\
\hline $\mathrm{AE}$ & 1 & $0,0 \%$ & $\mathrm{IE}$ & 1 & $0,0 \%$ \\
\hline $\mathrm{AU}$ & 9 & $0,2 \%$ & $\mathrm{IS}$ & 1 & $0,0 \%$ \\
\hline $\mathrm{BE}$ & 172 & $3,5 \%$ & $\mathrm{IT}$ & 192 & $3,9 \%$ \\
\hline $\mathrm{BM}$ & 43 & $0,9 \%$ & JP & 15 & $0,3 \%$ \\
\hline $\mathrm{CA}$ & 90 & $1,8 \%$ & $\mathrm{KY}$ & 3 & $0,1 \%$ \\
\hline $\mathrm{CH}$ & 194 & $4,0 \%$ & $\mathrm{LU}$ & 30 & $0,6 \%$ \\
\hline $\mathrm{DE}$ & 471 & $9,6 \%$ & n.a. & 36 & $0,7 \%$ \\
\hline $\mathrm{DK}$ & 29 & $0,6 \%$ & $\mathrm{NL}$ & 126 & $2,6 \%$ \\
\hline ES & 30 & $0,6 \%$ & $\mathrm{NO}$ & 77 & $1,6 \%$ \\
\hline FI & 16 & $0,3 \%$ & $\mathrm{SE}$ & 93 & $1,9 \%$ \\
\hline FR & 1.614 & $32,9 \%$ & US & 1.084 & $22,1 \%$ \\
\hline
\end{tabular}

Frecuencia total: 4.908

\begin{tabular}{lll}
\hline AD: Andorra & DK: Dinamarca & \\
AE: Emiratos Árabes & ES: España & JP: Japón \\
Unidos & FI: Finlandia & KU: Islas Caimán \\
AU: Australia & FR: Francia & n.a.: No disponible \\
BE: Bélgica & GB: Gran Bretaña & NL: Holanda \\
BM: Bermudas & IE: Irlanda & NO: Noruega \\
CA: Canadá & IS: Islandia & SE: Suecia \\
CH: Suiza & IT: Italia & US: Estados Unidos \\
DE: Alemania & &
\end{tabular}


Tabla 19. Distribución por países de los accionistas de las empresas españolas

\begin{tabular}{lcc|lcc}
\hline País & Frecuencia & Porcentaje & País & Frecuencia & Porcentaje \\
\hline AD & 23 & $0,4 \%$ & IS & 1 & $0,0 \%$ \\
\hline AE & 2 & $0,0 \%$ & IT & 73 & $1,4 \%$ \\
\hline AN & 1 & $0,0 \%$ & JP & 6 & $0,1 \%$ \\
\hline AR & 3 & $0,1 \%$ & KY & 22 & $0,4 \%$ \\
\hline AT & 1 & $0,0 \%$ & LU & 27 & $0,5 \%$ \\
\hline AU & 6 & $0,1 \%$ & MA & 1 & $0,0 \mathrm{v}$ \\
\hline BE & 78 & $1,5 \%$ & MX & 5 & $0,1 \%$ \\
\hline BM & 63 & $1,2 \%$ & n.a. & 79 & $1,5 \%$ \\
\hline BR & 5 & $0,1 \%$ & n.d. & 1 & $0,0 \%$ \\
\hline CA & 27 & $0,5 \%$ & NL & 104 & $2,0 \%$ \\
\hline CH & 100 & $1,9 \%$ & NO & 84 & $1,6 \%$ \\
\hline DE & 154 & $3,0 \%$ & NZ & 2 & $0,0 \%$ \\
\hline DK & 7 & $0,1 \%$ & OM & 1 & $0,0 \%$ \\
\hline ES & 2.980 & $57,9 \%$ & PE & 2 & $0,0 \%$ \\
\hline FI & 4 & $0,1 \%$ & PT & 61 & $1,2 \%$ \\
\hline FR & 222 & $4,3 \%$ & SE & 45 & $0,9 \%$ \\
\hline GB & 353 & $6,9 \%$ & TW & 1 & $0,0 \%$ \\
\hline GR & 1 & $0,0 \%$ & US & 575 & $11,2 \%$ \\
\hline HK & 1 & $0,0 \%$ & VG & 2 & $0,0 \%$ \\
\hline IE & 16 & $0,3 \%$ & ZA & 7 & $0,1 \%$ \\
\hline IL & 1 & $0,0 \%$ & ZW & 1 & $0,0 \%$ \\
\hline
\end{tabular}

Frecuencia total: 5.149

\begin{tabular}{llll}
\hline AD: Andorra & CH: Suiza & IS: Islandia & OM: Omán \\
AE: Emiratos Árabes & DE: Alemania & IT: Italia & PE: Perú \\
Unidos & DK: Dinamarca & JP: Japón & PT: Portugal \\
AN: Antillas Holandesas & ES: España & KY: Islas Caimán & SE: Sueciá \\
AR: Argentina & FI: Finlandia & LU: Luxemburgo & TW: Taiwán \\
AT: Austria & FR: Francia & MA: Marruecos & US: Estados \\
AU: Australia & GB: Gran Bretaña & MX: México & Unidos \\
BE: Bélgica & GR: Grecia & n.a.: No disponible & VG: Islas Vírgenes \\
BM: Bermudas & HK: Hong Kong & NL: Holanda & ZA: África del Sur \\
BR: Brasil & IE: Irlanda & NO: Noruega & ZW: Zimbabue \\
CA: Canadá & IL: Israel & NZ: Nueva Zelanda & \\
& & &
\end{tabular}

En Francia 32,9\% de los accionistas son franceses y 67,1\% son extranjeros. En España 57,9\% de los accionistas de las empresas son inversores españoles y $42,1 \%$ no lo son ( $1,5 \%$ de accionistas sin clasificación por país con las etiquetas n.d o n.a son extranjeras). Además, 4,2\% de los accionistas de las empresas españolas son inversores franceses, mientras que solo $0,6 \%$ de los inversores en las empresas francesas son españoles. 
Ya en el año 2000 Morin llamó la atención sobre el peso de los inversores extranjeros en Francia y el cambio que había experimentado este país en cuanto a su estructura de propiedad. Tradicionalmente, Francia se venía caracterizando por una red financiera, con el centro de las relaciones capitalistas ocupado por el Estado, en primer lugar, y subsiguientemente, por las participaciones cruzadas. Sin embrago, los datos de Morin desvelaron un cambio en dicho panorama, consistente, entre otras cosas, en la importante presencia de los inversores institucionales extranjeros, especialmente anglosajones, en las grandes empresas. En palabras del autor, Francia había pasado de ser una "economía de red financiera" a una "economía de mercado financiero" (Morin 2000: 37) y las justificaciones que el autor encontraba, al protagonismo incremental de los inversores extranjeros en la bolsa parisina, eran la apertura del sistema de regulación y la globalización de los mercados financieros y monetarios.

Un aspecto esencial del estudio de los accionistas de las empresas españolas y francesas es la consideración del número de inversiones de cada accionista, desglosado por países. Las tablas siguientes donde se distinguen los accionistas nacionales de los que no lo son, merecen atención:

Tabla 20. Inversiones en Francia por intervalos

\begin{tabular}{|c|c|c|c|}
\hline $\mathrm{N}^{\mathrm{o}}$ Inversiones & Franceses & No franceses & Total \\
\hline \multirow[t]{2}{*}{ de 1 a 5} & $89,43 \%$ & $76,36 \%$ & \\
\hline & $47,07 \%$ & $52,93 \%$ & $100 \%$ \\
\hline \multirow[t]{2}{*}{ de 6 a 10} & 3,71 & 7,59 & \\
\hline & $27,08 \%$ & $72,92 \%$ & $100 \%$ \\
\hline \multirow[t]{2}{*}{ de 11 a 20} & 2,57 & 5,86 & \\
\hline & $25,00 \%$ & $75,00 \%$ & $100 \%$ \\
\hline \multirow[t]{2}{*}{ de 21 a 50} & 1,71 & 7,59 & \\
\hline & $14,63 \%$ & $85,37 \%$ & $100 \%$ \\
\hline \multirow[t]{2}{*}{ de 51 a 112} & 2,57 & 2,60 & \\
\hline & $42,86 \%$ & $57,14 \%$ & $100 \%$ \\
\hline \multirow[t]{2}{*}{ TOTAL } & $100 \%$ & $100 \%$ & \\
\hline & $43,16 \%$ & $56,84 \%$ & $100 \%$ \\
\hline
\end{tabular}

En cursiva las inversiones expresadas en porcentaje sobre el total del intervalo. 
Tabla 21. Inversiones en España por intervalos

\begin{tabular}{|c|c|c|c|}
\hline $\mathrm{N}^{\mathrm{o}}$ Inversiones & Españoles & No españoles & Total \\
\hline \multirow[t]{2}{*}{ de 1 a 5} & $95,87 \%$ & $91,20 \%$ & \\
\hline & $71,32 \%$ & $28,68 \%$ & $100 \%$ \\
\hline \multirow[t]{2}{*}{ de 6 a 10} & $2,77 \%$ & $3,21 \%$ & \\
\hline & $67,14 \%$ & $32,86 \%$ & $100 \%$ \\
\hline \multirow[t]{2}{*}{ de 11 a 20} & $0,89 \%$ & $3,21 \%$ & \\
\hline & $39,47 \%$ & $60,53 \%$ & $100 \%$ \\
\hline \multirow[t]{2}{*}{ de 21 a 50} & $0,41 \%$ & $1,96 \%$ & \\
\hline & $33,33 \%$ & $66,67 \%$ & $100 \%$ \\
\hline \multirow[t]{2}{*}{ de 51 a 76} & $0,06 \%$ & $0,42 \%$ & \\
\hline & $25 \%$ & $75 \%$ & $100 \%$ \\
\hline \multirow[t]{2}{*}{ TOTAL } & $100 \%$ & $100 \%$ & \\
\hline & $70,29 \%$ & $29,71 \%$ & $100 \%$ \\
\hline
\end{tabular}

En cursiva las inversiones expresadas en porcentaje sobre el total del intervalo.

Como se ve, del 100\% de inversiones, tanto en Francia como en España, los accionistas nacionales, que son la mayoría, están concentrados en el intervalo de entre una y cinco inversiones. Cuando el número de inversiones por accionista aumenta, los accionistas extranjeros - no franceses y no españoles- están más representados que los nacionales. Las tablas siguientes resumen las precedentes:

Tabla 22. Inversiones en Francia en dos intervalos

\begin{tabular}{lccc}
\hline $\mathrm{N}^{\mathrm{o}}$ Inversiones & Franceses & No franceses & Total $^{1}$ \\
\hline de 1 a 5 & $89,43 \%$ & $76,36 \%$ & $82,00 \%$ \\
de 6 al máximo & $10,57 \%$ & $23,64 \%$ & $18 \%$ \\
\hline TOTAL & $100 \%$ & $100 \%$ & $100 \%$ \\
\hline
\end{tabular}

Tabla 23. Inversiones en España en dos intervalos

\begin{tabular}{lccc}
\hline № Inversiones & Españoles & No españoles & Total $^{1}$ \\
\hline de 1 a 5 & $95,87 \%$ & $91,20 \%$ & $94,48 \%$ \\
de 6 al máximo & $4,13 \%$ & $8,80 \%$ & $5,52 \%$ \\
\hline TOTAL & $100 \%$ & $100 \%$ & $100 \%$ \\
\hline${ }^{1}$ Porcentaje sobre el total de las inversiones en España. & \\
\hline
\end{tabular}


Se aprecia que las empresas extranjeras más que duplican su presencia en los niveles altos del número de inversiones por accionista, tanto en el caso francés como en el español: $23,64 \%$ no francesas contra $10,57 \%$ francesas y en el accionariado de las empresas españolas, $8,80 \%$ contra $4,13 \%$.

Podemos examinar los mismos datos en otra perspectiva, es decir del total inversiones por intervalos, distinguir las inversiones efectuadas por accionistas nacionales de las realizadas por accionistas extranjero (ver tablas 20 y 21). Los resultados son suficientemente expresivos: salvo en el intervalo de 1 a 5 inversiones por accionista, donde las empresas nacionales son mayoritarias, en los demás intervalos lo son las extranjeras.

Conviene apuntar que los datos que utilizamos presentan considerables dificultades en cuanto a la identificación precisa de los inversores: las filiales nacionales de las empresas transnacionales se consideran distintas de la sociedad madre, así como entre ellas. Esto conduce a una sobrestimación del número de accionistas nacionales y, también, a una subestimación de los accionistas comunes entre las empresas francesas y españolas.

\subsubsection{Los accionistas comunes a las empresas españolas y francesas y sus características}

Contemplamos ahora los accionistas que las empresas españolas y francesas, aquí consideradas, tienen en común. Hemos identificado 73 accionistas comunes. Ese número representa un $9 \%$ de los accionistas totales de las empresas francesas y un 3\% de las españolas.

Esos 73 accionistas comunes de las empresas españolas y francesas tienen las siguientes características en cuanto a su distribución por categorías de accionistas y por países, pero hay que recordar que todos los accionistas comunes son actores económicos globales, aun cuando algunos sean españoles $o$ franceses.

Tabla 24. Accionistas comunes por país de origen y categoría

\begin{tabular}{|c|c|c|c|c|c|c|c|}
\hline \multirow{2}{*}{ País } & \multicolumn{6}{|c|}{ Categorías } & \multirow{2}{*}{$\%$ Total } \\
\hline & Bancos & Estados & Financieras & $\begin{array}{l}\text { Fondos } \\
\text { Inversión }\end{array}$ & Industriales & Seguros & \\
\hline $\mathrm{BE}$ & & & & $1,4 \%$ & $1,4 \%$ & & $2,7 \%$ \\
\hline $\mathrm{BM}$ & $1,4 \%$ & & $1,4 \%$ & & & & $2,7 \%$ \\
\hline $\mathrm{CH}$ & & & & $2,7 \%$ & $1,4 \%$ & & $4,1 \%$ \\
\hline $\mathrm{DE}$ & $4,1 \%$ & & & $1,4 \%$ & & & $5,5 \%$ \\
\hline ES & $5,5 \%$ & & $4,1 \%$ & $4,1 \%$ & & $1,4 \%$ & $15,1 \%$ \\
\hline FR & $9,6 \%$ & & $2,7 \%$ & & & & $12,3 \%$ \\
\hline
\end{tabular}




\begin{tabular}{|c|c|c|c|c|c|c|c|}
\hline \multirow[b]{2}{*}{ País } & \multicolumn{6}{|c|}{ Categorías } & \multirow[b]{2}{*}{$\%$ Total } \\
\hline & Bancos & Estados & Financieras & $\begin{array}{c}\text { Fondos } \\
\text { Inversión }\end{array}$ & Industriales & Seguros & \\
\hline GB & $9,6 \%$ & & $5,5 \%$ & $2,7 \%$ & $1,4 \%$ & $1,4 \%$ & $20,5 \%$ \\
\hline IT & $1,4 \%$ & & & $1,4 \%$ & & & $2,7 \%$ \\
\hline KY & & & & $1,4 \%$ & & & $1,4 \%$ \\
\hline $\mathrm{LU}$ & & & & & $1,4 \%$ & & $1,4 \%$ \\
\hline NL & $1,4 \%$ & & & & & & $1,4 \%$ \\
\hline $\mathrm{NO}$ & & $1,4 \%$ & & & & & $1,4 \%$ \\
\hline SE & $1,4 \%$ & & & & & & $1,4 \%$ \\
\hline US & $17,8 \%$ & & $4,1 \%$ & $4,1 \%$ & & $1,4 \%$ & $27,4 \%$ \\
\hline TOTAL & $52,1 \%$ & $1,4 \%$ & $17,8 \%$ & $19,2 \%$ & $5,5 \%$ & $4,1 \%$ & $100,0 \%$ \\
\hline \multicolumn{2}{|c|}{$\begin{array}{l}\text { BE: Bélgica } \\
\text { BM: Bermudas } \\
\text { CH: Suiza } \\
\text { DE: Alemania }\end{array}$} & \multicolumn{2}{|c|}{$\begin{array}{l}\text { ES: España } \\
\text { FR: Francia } \\
\text { GB: Gran Bretaña } \\
\text { IT: Italia }\end{array}$} & \multicolumn{2}{|c|}{$\begin{array}{l}\text { KY: Islas Caimán } \\
\text { LU: Luxemburgo } \\
\text { NL: Holanda } \\
\text { NO: Noruega }\end{array}$} & \multicolumn{2}{|c|}{$\begin{array}{l}\text { SE: Suecia } \\
\text { US: Estados Unidos }\end{array}$} \\
\hline
\end{tabular}

Resulta interesante comparar entre los países el número medio de participaciones que tienen estas categorías de inversores. La tabla siguiente expresa el número de participaciones que los accionistas de cada sector tienen en las empresas españolas y francesas, así como el promedio de empresas en las que invierten los accionistas de cada categoría.

Tabla 25.Participaciones en Francia y España por tipo de accionista

\begin{tabular}{lccccc}
\hline $\begin{array}{l}\text { Tipo de } \\
\text { accionista }\end{array}$ & Frecuencia & $\begin{array}{c}\text { Participaciones } \\
\text { Francia }\end{array}$ & $\begin{array}{c}\text { Participaciones } \\
\text { España }\end{array}$ & $\begin{array}{c}\text { Participación } \\
\text { total }\end{array}$ & $\begin{array}{c}\text { Participación } \\
\text { media }\end{array}$ \\
\hline Bancos & 38 & 850 & 500 & 1350 & 35,53 \\
Fondos & 13 & 272 & 65 & 337 & 25,92 \\
inversión & 14 & 204 & 65 & 269 & 24,45 \\
Financieras & 4 & 119 & 44 & 163 & 40,75 \\
Seguros & 4 & 156 & 31 & 187 & 46,75 \\
Industriales & 1 & 68 & 77 & 145 & 145 \\
Fondos & 1 & 1669 & 782 & 2451 & 34,52 \\
soberanos & 73 & & & & \\
\hline TOTAL & & & & &
\end{tabular}

Es evidente que el sector financiero, bancos, fondos de inversión, empresas financieras, compañías de seguros y fondos soberanos son los accionistas más importantes; las empresas industriales son 4 y restando sus participaciones, 187, al total, se ve claramente que su peso es pequeño en la estructura accionarial.

Como hemos visto más arriba al considerar las participaciones de la totalidad de accionistas de las empresas españolas o francesas, las participaciones de accionistas industriales estimados en porcentajes es mayor que las que aparecen 
para los accionistas comunes, y el peso del resto de sectores, los financieros, es consecuentemente menor.

\section{CONCLUSIONES Y DISCUSIÓN: LA DIMENSIÓN NACIONAL EN LAS ESTRUCTURAS ECONÓMICAS}

A la vista de los precedentes análisis lo que está claro es que, considerando las redes de relaciones creadas por los accionistas comunes entre las empresas $y$, de manera dual, las relaciones entre accionistas que invierten en las mismas empresas, nos encontramos con redes extremadamente conexas, con una densidad inusitada y con una media de distancias entre puntos muy baja. Es decir, que todo apunta hacia una unificación estructural del mundo empresarial desde el punto de vista financiero. Vitali et al. (2011), examinando decenas de miles de las mayores empresas del mundo, llegan a las mismas conclusiones que nosotros.

Además, que esa unificación estructural se produce cuando los accionistas de las empresas de ambos países son, en proporciones muy altas, extranjeros. $\mathrm{O}$, dicho en otros términos: la diversidad de nacionalidad de los accionistas no disminuye la cohesión de las redes empresariales con empresas vinculadas por accionistas comunes.

Distinta situación aparece cuando se consideran las redes de consejeros: los consejeros de las empresas francesas son franceses, los de las españolas, españoles. Pero las redes de empresas relacionadas por consejeros comunes son menos conexas que las de empresas vinculadas por accionistas comunes y sus densidades relativamente bajas. Y, al parecer, esta circunstancia no es puntual, ya que a partir de trabajos como los de Heinze (2004), Heemskerk (2007), Heemskerk y Fennema (2009), Chu y Davis (2011) o Romano y Favino (2013) se deduce que la densidad de las redes de empresas conectadas por consejeros comunes ha disminuido sin cesar en las cuatro últimas décadas.

Los datos disponibles sobre los grandes inversores institucionales llevan a la conclusión inevitable de que éstos no pueden ejercer el control sobre las empresas participadas mediantes la designación de consejeros: necesitarían ejércitos de consejeros de varios miles de personas, y tales conjuntos de individuos serían difíciles de coordinar y orientar. Es obvio que la regulación y el control de las empresas participadas se ejercen por otros procedimientos. Y, por ello, las redes de consejeros pierden relevancia. El control subjetivo, control mediante sujetos, mediante agentes que representan intereses, está perdiendo importancia, mientras que otras formas de regulación, principalmente de carácter normativo, cobran una importancia creciente.

Aun así, los consejeros de las empresas constituyen la principal dimensión nacional de las estructuras económicas y se piensan como sujetos de la acción económica y, en última instancia, como sujetos políticos.

Como apuntábamos anteriormente, el poder se sigue concibiendo como atributo de sujetos más que como una característica propia de la estructura 
social. Investigar el poder sigue siendo para muchos identificar a sus detentores. Las investigaciones sobre las redes empresariales buscan esa localización e identificación de conjuntos de individuos, elites económicas supuestamente capaces de explicar los acontecimientos y los actos. Sin embargo, la identificación de esos grupos de individuos no nos lleva muy lejos en nuestro propósito de comprender la realidad social y sus transformaciones. La identificación es más investigación policial que indagación científica. Y lo mismo podría afirmarse de la identificación de las personas jurídicas, entidades extremadamente plásticas que se crean, se modifican, se fusionan o se separan.

Las ciencias sociales se mueven en el ámbito de la ideología, cosifican los procesos sociales que se dan en las estructuras y toman como objetos entidades efímeras, cuya duración temporal es corta: no sólo los seres humanos, sino que, además, esas entidades de derecho que son las empresas e incluso los Estados nacionales son tan mortales como mujeres y hombres. No podremos entender la realidad identificando personas, naturales o jurídicas, que desaparecen antes de que acabemos la recogida de datos.

El presente trabajo propicia múltiples ampliaciones en futuras investigaciones, tanto en número de países objeto de estudio, como en profundización y detalle del análisis mediante, por ejemplo, el estudio de sectores, de consideración de los pesos de las propiedades, de búsqueda de efectos económicos de las conexiones o de las causas que los originan, etc. De entre todas las opciones posibles, tenemos especial interés en completar la investigación con la determinación de los denominados lugares, las redes de lugares y las equivalencias estructurales. Se entiende por lugares el subconjunto de los grupos a los que pertenece un individuo, contenido en el conjunto de todos los grupos a los que pertenecen todas las personas en la red, mientras que la equivalencia estructural implica que dos individuos pertenezcan exactamente a las mismas instituciones. Este enfoque, entre otras cuestiones, nos permitiría determinar dónde tiene que sentarse un consejero o dónde debe invertir un accionista para ostentar el máximo protagonismo en términos de poder o control.

\section{BIBLIOGRAFÍA}

Baena, M. \& Pizarro N. (1985): "The Structure of the Spanish Political Elite, 19391975", en Research in Politics and Society, New York, JAI Press, Inc., pp. 149-171.

Baena, M., Garrido, L. \& Pizarro, N. (1984): "Los burócratas en la élite española", Documentación Administrativa, 200, pp. 73-133.

Bazerman, M.H. \& Schoorman, F.D. (1983) "A Limited Rationality Model of Interlocking Directorates", Academy of Management Review, 8 (2), pp. 206-217.

Berle A. A. \& Means G.C. (1944): The modern corporation and private property, New York, Macmillan.

Brayshay, M., Cleary M. \& Selwood J. (2006): "Power Geometries: Social networks and the 1930s multinational corporate elite", Geoforum, 37, pp. 968-998. 
Brayshay, M., Cleary M. \& Selwood J. (2007): "Social networks and the transnational reach of the corporate class in the early-twentieth century", Journal of Historical Geography, 33, pp. 144-167.

Breiger, R. (1974): “The Duality of Persons and Groups", Social Forces, 52, pp. 181190.

Burham, J. (1941): The managerial revolution: What is happening in the world, New York, The John Day Company, cop.

Burris, V., Staples C. (2012): "In search of a transnational capitalist class: Alternative methods for comparing director interlocks within and between nations and regions", International Journal of Comparative Sociology, 53, pp. 323-342.

Burris, V. (2005): "Interlocking Directorates and Political Cohesion among Corporate Elites", American Journal of Sociology, 111 (1): 249-283.

Carroll, W. K. (2009): "Transnationalists and nacional networkers in the global corporate elite", Global Networks, 9 (3), pp. 289-314.

Carroll, W.K. \& Sapinski, J.P. (2010): “The Global Corporate Elite and the Transnational Policy-Planning Network, 1996-2006. A Structural Analysis", International Sociology, 25(4), pp. 501-538.

Carroll, W.K. \& Sapinski, J.P. (2011): “Corporate elites and Intercorporate Networks", en The Sage Handbook of Social Network Analysis, Londres, Sage, pp. 180-195.

Chu, J. S. G. \& Davis, G. F., (2011): "Who Killed the Inner Circle? The Breakdown of the American Corporate Elite Network, 1999-2009", Paper 1, disponible en http:// opensiuc.lib.siu.edu/pnconfs_2011/1 [consulta: 10/12/2013]

Comet, C. \& Pizarro, N. (2011): "The cohesion of intercorporate networks in France", Procedia Social and Behavioral Sciences, 10, pp. 52 -61.

Connelly, B.L. VanSlyke, E.J. (2012): "The power and peril of board interlocks", Business Horizons, 55, pp. 403-408.

Core, J., Halthausen, R. \& Larcker, D. (1999): “Corporate Governance, Chief Executive Officer Compensation and Firm Performance", Journal of Financial Economics, 43, pp. $195-218$

Cronin, B. (2011): "Networks of corporate power revisited", Procedia Social and Behavioral Sciences, 10, pp. 43-51.

Garmendia, A. \& Del Orden, O. (2008): "Estructuras de Propiedad y Grupos Empresariales en España”, Ekonomiaz, 68 (2), pp. 102-133

Domhoff, G.W. (1967): Who Rules America?. Englewood Cliffs, New York, PrenticeHall.

Domhoff, G.W. (1970): The Higher Circles, New York, Vintage Books.

Domhoff, G.W. (1972): Fat Cats and Democrats, Englewood Cliffs, New York, PrenticeHall.

Domhoff, G.W. (1974): The Bohemian Grove and Other Retreats, New York, Harper \& Row.

Domhoff, G.W. (1987): "The Wagner Act and Theories of the State", Political Power and Social Theory, 6, pp. 159-185.

Federation of European Securities Exchanges (FESE) (2008): Share Ownership Structure in Europe, disponible en http://www.fese.eu/_lib/files/Share_Ownership_ Survey_2007_Final.pdf [consulta: 12/3/2011]

Ferris, S., Jagannathan M. \& Pritchard A. (2003): "Monitoring by Directors with Multiple Board Appointments", Journal of Finance, 58 (3), pp. 1087-1111.

Fich, E., \& Shivdasani, A. (2006): "Are busy boards effective monitors", Journal of Finance, 61, pp. 689-724. 
Gilo, D., Moshe, Y. \& Spiegel, Y. (2006): "Partial Cross Ownership and Tacit Collusion", RAND Journal of Economics, 37 (1), pp. 81-99.

Hardford, J., Jenter, D. \& Li, K. (2011): "Institutional cross-holdings and their effect on acquisition decisions", Journal of Financial Economics, 99 (1), pp. 27-39.

Heinze T. (2004): "Dynamics in the German system of corporate governance? Empirical findings regarding interlocking directorates", Economy and Society, 33 (2), pp. 218 238.

Heemskerk E. M. (2007): Decline of the Corporate Community. Network Dynamics of the Dutch Business Elite, Amsterdam, Amsterdam University Press.

Heemskerk, E. \& Fennema, M. (2009): "Network Dynamics of the Dutch Business Elite", International Sociology, 24 (6), pp. 807-832.

Koenig, T. \& Gogel, R. (1981): "Interlocking Corporate Directorships as a Social Network", The American Journal of Economics and Sociology, 40 (1), pp. 37-50.

Koenig, T., Gogel, R. \& Sonquist, J. (1979): "Models of the Significance of Interlocking Corporate Directorates", American Journal of Economics and Sociology, 38, pp. 173-186

Linklaters (2013): Activist investors turn up the heat in global boardrooms, disponible en http://www.linklaters.com/News/LatestNews/2013/Pages/Activist-investors-globalboardrooms.aspx[consulta: 16-6-2014]

Mills, C.W. (1956): The Power Elite, New York, Oxford University Press.

Mintz, B. \& Schwartz, M. (1981): "Interlocking directorates and interest group formation", American sociological review, 46, pp. 851-69.

Mizruchi, M. S. (1982): The American Corporate Network, 1904-1974, Beverly Hills, California.

Mizruchi, M. S. (1992): The Structure of Corporate Political Action, Cambridge, Mass, Harvard University Press.

Mizruchi, M. S. (1996): "What Do Interlocks Do? An Analysis, Critique, and Assessment of Research on Interlocking Directorates" Annual Review of Sociology, 22, pp. 271-298.

Mizruchi, M. S. \& Koenig T. (1986): "Economic Sources of Corporate Political Consensus. American Sociological Review", 51, pp. 482-491.

Morin, F. (2000): "A transformation in the French model of Shareholding and management", Economy and Society, 29 (1), pp. 36-53.

Newman M. E. J. (2003): "The Structure and Function of Complex Networks", SIAM review, 45, (2), pp. 167-256.

O’Hagan, S.B. \& Green, M.B. (2004): “Corporate knowledge transfer via interlocking directorates: a network analysis approach", Geoforum, 35, pp. 127-139.

Perry, T., \& Peyer, U. (2005): "Board seat accumulation by executives: A shareholder's perspective", Journal of Finance, 60, pp. 2083-2123.

Romano, M. \& Favino, C. (2013): "Board Composition and Interlocking Directorate Evolution as a Consequence of the Recent Financial Crisis: Evidence from Italian Listed Companies”, Ownership \& Control, 11 (1), pp. 175 - 192.

Stiglitz, J. E. (2010): "Risk and Global Economic Architecture: Why Full Financial Integration May Be Undesirable", NBER working paper.

Stokman F. N., Ziegler, R. \& Scott J. (Eds.) (1985): Networks of Corporate Power. A comparative analysis of ten countries, Polity Press and Basil Blackwell, Cambridge and Oxford. 
Trivieri, F. (2007): "Does Cross-Ownership Afect Competition? Evidence from the Italian Banking Industry, Journal of International Financial Markets, Institutions \& Money, 17, pp. 79-101.

Useem, M. (1984): The Inner Circle: Large Corporations and the Rise of Business Political Activity in the U.S. and U.K., New York, Oxford University Press.

Useem, M. (1996): Investor Capitalism: How Money Managers are Changing the Face of Corporate America, New York, Basic Books.

Vitali, S., Glattfelder, J. \& Battiston, S. (2011): The network of global corporate control, disponible en http://arxiv.org/abs/1107.5728v2 [consulta: 20-11-2013].

Windolf, P. (2002): Corporate networks in Europe and the United States, New York, Oxford University Press.

Zeitlin, M. (1974): "Corporate Ownership and Control: The Large Corporation and the Capitalist”, American Journal of Sociology, 79 (5), pp. 1073-1119. 